\title{
Microanatomy of the Terminal Air Spaces of Baird's Beaked Whale (Berardius bairdii) Lungs
}

\author{
Hiroyoshi NINOMIYA ${ }^{1)}$, Tomo INOMATA ${ }^{1)}$, Hiroshi SHIROUZU²) and Etsuko KATSUMATA ${ }^{3)}$ \\ ${ }^{1)}$ Department of Laboratory Animal Science, Azabu University, 1-17-71 Fuchinobe Sagamihara, Kanagawa 229-8501, ${ }^{2)}$ Taiji Whale \\ Museum, Taiji-cho Higashi Murou-gun, Wakayama 649-5100 and ${ }^{3)}$ Kamogawa Sea World, 1464-18 Higashicho Kamogawa, Chiba 296- \\ 0041, Japan
}

(Received 8 October 2004/Accepted 5 January 2005)

\begin{abstract}
The terminal airways and microvasculature of five adult Baird's beaked whales (Berardius bairdii) lungs have been examined by means of light and scanning electron microscopy of corrosion casts. The respiratory system of the Baird's beaked whale has various anatomical features which allow them to attain great depths and remain submerged for long periods. The whale lung has components including hyaline cartilage and smooth muscle throughout, reaching as far as the peripheral bronchi, sphincters surrounding the terminal bronchioles, the thick alveolar septa with a connective tissue core and a bi-layer capillary bed, and a distinctive venous plexus of the pulmonary veins. The well-developed venous plexuses of the pulmonary vein are found in the interlobular connective tissue, and around the airways and pulmonary arteries with close apposition. The hyaline cartilage throughout the airways may increase the effective dead air space that accommodates most of the air forced from the collapsed alveoli during a dive. The sphincter might serve as a cock for regulating buoyancy and for trapping air in the alveoli to prevent their complete collapse and a sucking in of alveolar tissue as the dive becomes deeper. The venous plexuses might be for pooling the large volume of blood in the lung to conserve oxygen for deep and prolonged diving.

KEY WORDS: Baird's whale, corrosion cast, functional anatomy, SEM, terminal airways.
\end{abstract}

Despite the rare opportunity to acquire cetacean fresh tissue suitable for research, gross observations on the pulmonary anatomy of several whale species have been reported $[10,12,14,15]$. In addition, detailed microanatomy of the terminal airways of both the bowhead whale (Balaena mysticetus) and the bottlenose dolphin (Tursiops truncatus) is available $[3,4,6,7,11,13]$. The respiratory system of whales shows various anatomical features which allow them to attain great depths and remain submerged for long periods. The respiratory anatomy of the whale includes lungs that undergo compression at depths $[4,17]$ and hyaline cartilage in the tracheobronchial tree as far as the peripheral bronchi $[4,7,8]$. The alveolar septa of the whales are thick with a connective tissue core and a bi-layer capillary bed. A double capillary network is regularly found in the alveolar duct and alveolar septa [4, 7]. One of the most noteworthy structures in cetacean lungs is the sphincters in the terminal bronchioles of most of the smaller toothed whales [4, 6]. In our previous report, we examined the microvasculature of the terminal airway of the Baird's whale and we clarified the existence of a bi-layer capillary bed in the alveolar walls and venules with flap-, funnel- and/or chimney like venous valves [16]. As we have yet very little information about the morphology of the three-dimensional structure of the whale's terminal airways, this report describes the microanatomy of the peripheral airways and alveoli. An attempt has been made to correlate these findings with the known physiological data to explain the diving ability of the Baird's whale, which can attain depths up to 1,000 meters and dive for as long as $60 \mathrm{~min}$.

\section{MATERIALS AND METHODS}

Animals: Lungs from five Baird's beaked whales (adult males) were examined.

All were harvested around Japan's coast by a whaling company in 2003. Lung samples were taken 18-20 hr after they were sacrificed. The material was not very well preserved, but all essential characteristics could be determined. This whaling was authorized by the Fisheries Agency of Japan in accordance with national regulations, and the biological surveys of each whale caught were conducted by the National Research Institute of Far Seas Fisheries (NRIFSF). Samples used in this study were authorized and obtained in cooperation with the NRIFSF, the whaling company and the Fisheries Agency of Japan.

Injection of resin: A cannula was tied into either the pulmonary artery or bronchus. The vascular bed was flushed with $0.9 \% \mathrm{NaCl}$ from the pulmonary artery. Through the same catheter, a combination of methylmethacrylate monomer and Mercox (ratio in volume $=8: 2$; Dainippon Ink \& Chemicals, Tokyo, Japan) was subsequently injected. This was followed by filling the airway with the combined resin with red pigment added. While resin was injected with a syringe under manual pressure, no attempt was made to measure the applied pressure. Then, the injected sector was placed in a water bath at $40^{\circ} \mathrm{C}$ for approximately $30 \mathrm{~min}$ to allow the resin to harden. Corrosion of the injected lung was accomplished by immersing in $20 \% \mathrm{NaOH}$ over a few days. After dissolution of the tissues, the corroded casts were thoroughly and repeatedly washed in running tap water. Individual pieces of larger lung casts were placed in plastic cups 
and frozen in distilled water. The frozen blocks were cut into slices, 2-3 mm thick, with a fretsaw. After being airdried at room temperature, the casts were mounted on aluminum stubs, sputter-coated with gold and examined with a scanning electron microscope (ABT-32; Topkon Co., Ltd., Tokyo, Japan).

Histologic observation: Other pieces of lung were fixed in $10 \%$ formalin. Then the tissue was dissected out, dehydrated in ethanol and embedded in paraffin wax. A series of $5 \mu \mathrm{m}$ sections was cut and stained with hematoxylin and eosin, or Azan Mallory.

\section{RESULTS}

The pattern of airway distribution and the respiratory portion of the Baird's whale lung system correspond to those found in the terrestrial mammalian respiratory system, both at the gross and microscopic levels.

Bronchi: Histologically, the bronchi are lined with pseudostratified columnar ciliated epithelium. The rings and plates of cartilage in the bronchi continue down to the smallest branches of the bronchial tree. This cartilage is generally more pronounced in airways with luminal diameters greater than $5 \mathrm{~mm}$ (Fig. 1). Most of the distal bronchi (1.0-0.5 mm in diameter) do not contain these rings of cartilage, but rather are characterized by irregular crescent structures situated obliquely within the walls (Fig. 2). Smooth muscle extends to the level of the terminal bronchioles. Well-developed venous plexuses are seen between the cartilage and the internal elastic lamina immediately beneath the epithelium of the airways. The venous plexuses consist of many thinwalled venules and continue as far as the terminal portions of bronchi (Figs. 1, 2).

In corrosion casts, branching of the bronchi is mostly dichotomous and almost exclusively acute-angled. Each bronchus divides into segmental bronchi supplying the bronchopulmonary segments of the lobe. The segmental bronchi continually subdivide into the terminal bronchi. The bronchi have serial circular constrictions along the course of the tracheobronchial tree, representing cartilaginous rings (Fig. 3). Segments between the constrictions, representing the regions devoid of cartilaginous support, are dilated by the injected resin. The bulging feature on the cast surface is sometimes particularly pronounced, reminding us of a bellows form. In addition, the casts of the bronchi sometimes show a fine corrugation of longitudinally oriented stripes representing the mucous membranes arranged into longitudinal folds.

Bronchioles and alveoli: Histologically, the terminal and respiratory bronchioles are devoid of the cartilaginous support. They are lined with a simple epithelium. A thick smooth muscle layer containing elastic fibers is present in the terminal and respiratory bronchioles, completely encircling the lumen of the bronchiole and forming a prominent myoelastic sphincter at the entrance of the alveolar ducts, with their lumens nearly occluded (Figs. 4, 5). The alveolar ducts and alveolar septa contain the typical cetacean double

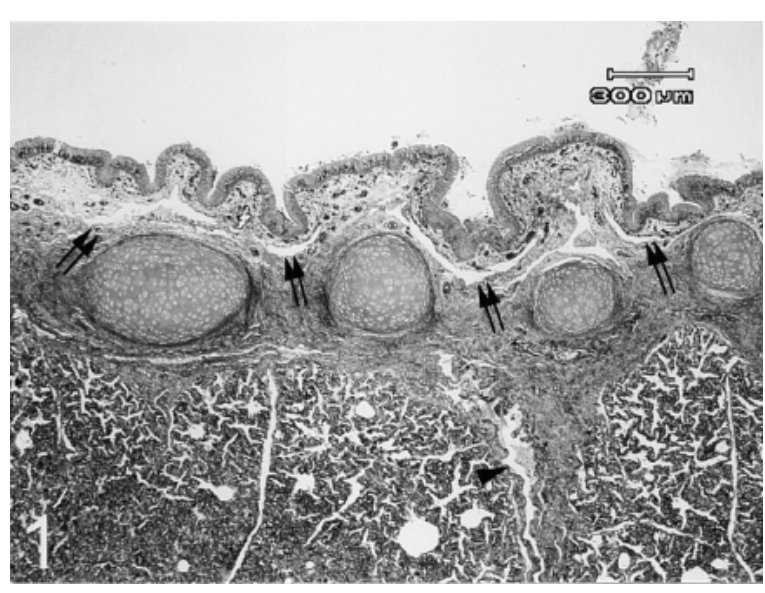

Fig. 1. Longitudinal section of a bronchus, $5 \mathrm{~mm}$ in diameter, showing the venous plexus of the pulmonary veins beneath the ciliated epithelium (double arrows) and the cartilages. A distinctive plexus of the pulmonary veins is seen in the interlobular connective tissue (arrow head). Azan Mallory stain. Bar = $300 \mu \mathrm{m}$.

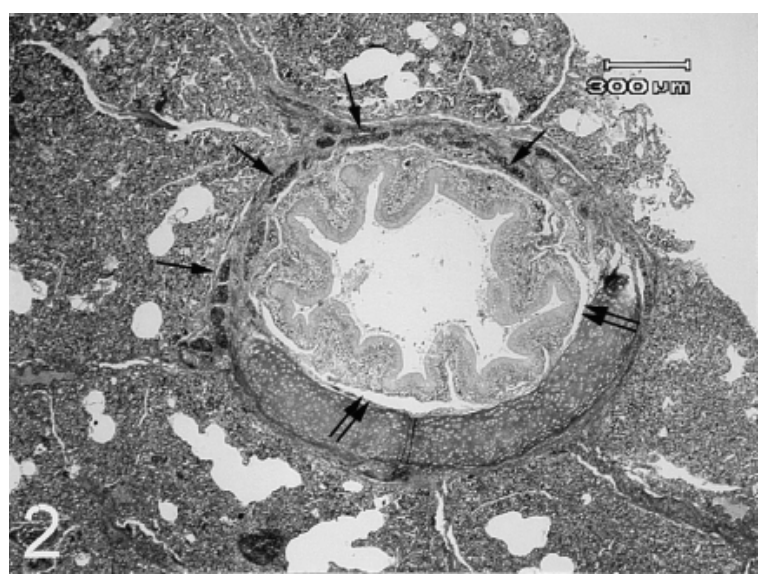

Fig. 2. Cross section of a terminal bronchus, $0.5 \mathrm{~mm}$ in diameter, showing the crescentric cartilage and smooth muscles (arrows). Note that the submucosa is still quite vascular (double arrows). Azan Mallory stain. Bar $=300 \mu \mathrm{m}$.

capillary bed separated by a thick septum composed mainly of collagenous connective tissue (Fig. 6). The alveolar surface was lined with a thin cytoplasmic extension of respiratory epithelial cells lining the alveolar capillaries.

In corrosion casts, the terminal bronchioles end in a trifurcation and give rise to 4 or 5 generations of thick, short branches, representing respiratory bronchioles (Fig.7). Then, they divide into several alveolar ducts, each of which gives rise to a cluster of alveolar saccules (Fig. 8). These clusters are so closely packed that it is almost impossible to identify their branches beyond the main division of each. The transitional region from a respiratory bronchiole to a cluster of alveolar saccules has 2-3 consecutive marked strangulations (90-150 $\mu \mathrm{m}$ in diameter), representing the 


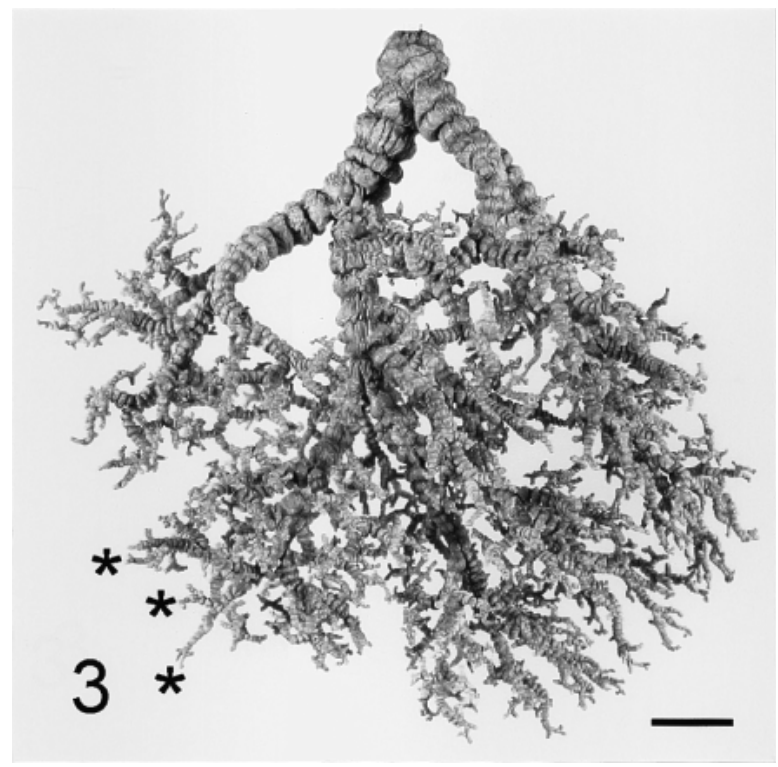

Fig. 3. A corrosion cast of the segmental bronchi. The asterisk indicates the terminal bronchi from which SEM photographs were taken and shown in Figs. 7, 8, 11. Bar $=20 \mathrm{~mm}$.

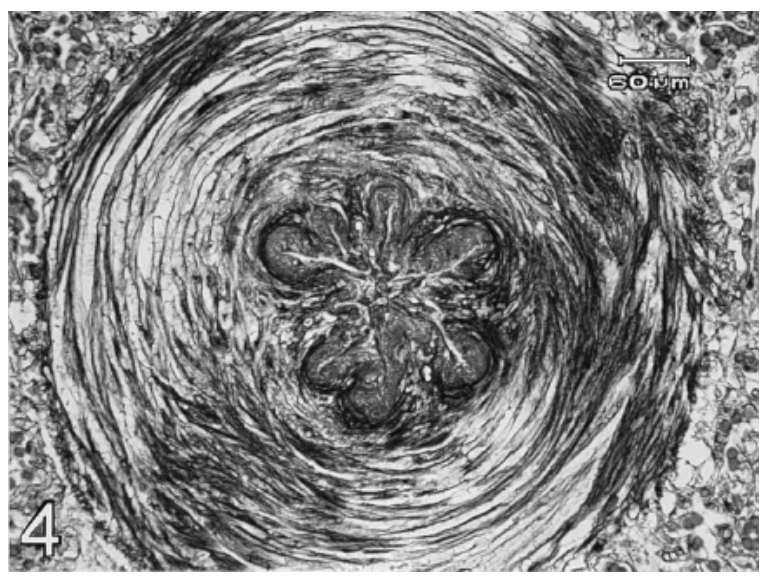

Fig. 4. Cross section of a myoelastic sphincter at a terminal bronchiole. $\mathrm{Bar}=60 \mu \mathrm{m}$.

myoelastic sphincters (Figs. 7, 8).

Microvasculature: Histologically, the small pulmonary veins converging collecting venules were observed in the interlobular connective tissue. In extralobular location, the pulmonary veins are closely associated with the air passages and the pulmonary arteries. Within a distinct pulmonary lobule this association is less marked, and veins course singly through the interlobular connective tissue and form distinct venous plexuses (Fig. 1). Most of the vessels of the plexuses and arteries are in close apposition and the intervascular tissue is a few fibroblasts (Fig. 9). The distance between the lumens of the venous plexuses and arteries is up to $150 \mu \mathrm{m}$.

In corrosion casts, the pulmonary arteries and their

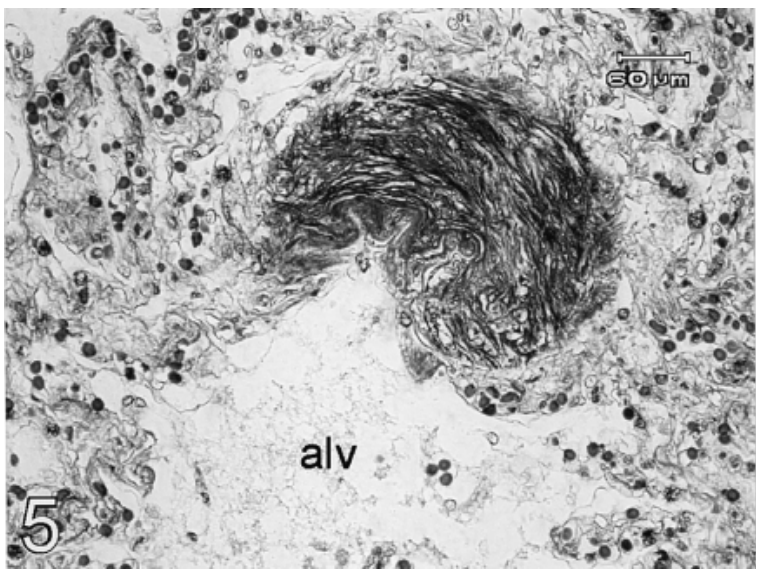

Fig. 5. Longitudinal section of a sphincter and an alveolar saccule (alv). Azan Mallory stain. Bar $=60 \mu \mathrm{m}$.

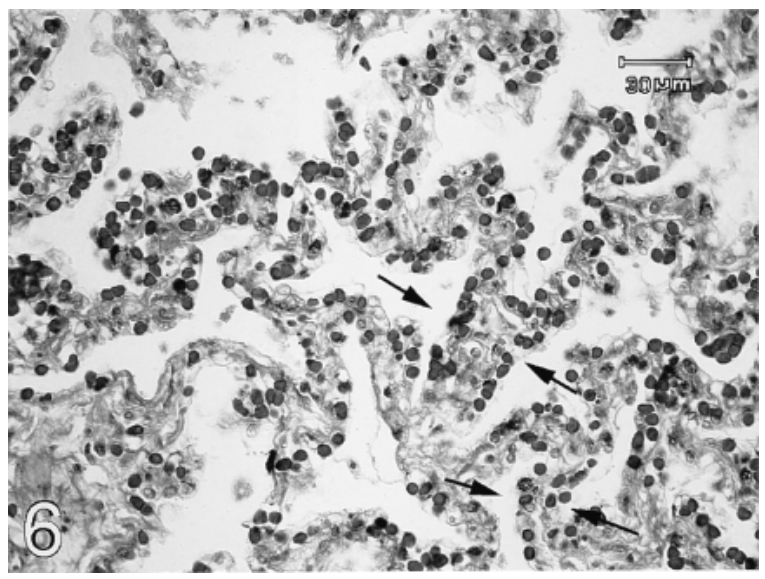

Fig. 6. Alveolar walls with a double capillary layer (arrows). Azan Mallory stain. Bar $=30 \mu \mathrm{m}$.

branches follow the bronchial tree to supply blood to the peripheral margin of the lobes. The capillaries in the lung parenchyma form characteristic baskets in relation to the alveolar structures. The mean diameter of the capillaries was $9-11 \mu \mathrm{m}$. The alveolar ducts and large parts of the septal microvasculature appear as trilayered structures with two distinct capillary networks, sandwiching the connective tissue core, which had been digested away. Septa at the very end of the alveoli, adjacent to the pleura, the larger vessels, or the bronchi, show only a single capillary layer (Fig. 10). Collecting or postcapillary venules, being jointed by the capillaries, gradually increased in luminal diameter from 10 to $25 \mu \mathrm{m}$. The collecting venules in turn converge, forming pulmonary venules which have a luminal size up to $200 \mu \mathrm{m}$. These pulmonary venules join gradually with other venules to form increasingly larger veins which converge into the pulmonary veins of $200-500 \mu \mathrm{m}$ in diameter. The pulmonary veins run in the peribronchial connective tissue and in the interlobular connective tissue. They increase in size mainly by conversion of equally sized roots and form a well- 


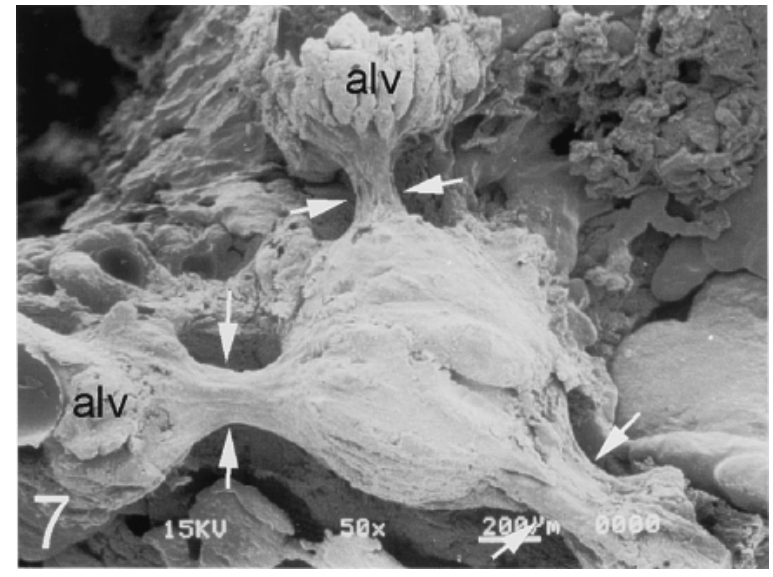

Fig. 7. Corrosion cast of a terminal bronchiole with two clusters of alveolar saccules (alv). Marked constrictions locating between the terminal bronchiole and the alveolar sacs are made by the existence of myoelastic sphincter system (arrows). Bar $=200 \mu \mathrm{m}$.

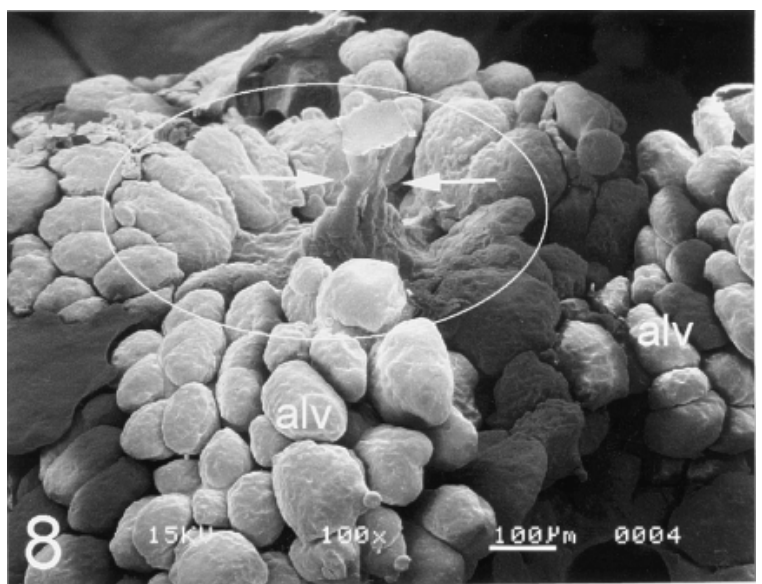

Fig. 8. Corrosion cast of two clusters of alveolar saccules (alv). The alveolar saccule looks like a bunch of grapes. A respiratory bronchiole (arrows) is seen in the left alveolar cluster. A concave area around the bronchiole represents a sphincter (encircled zone). Bar $=100 \mu \mathrm{m}$.

developed venous plexus surrounding the bronchi (Fig. 11) and in the interlobular connective tissue (Fig. 12). These venous plexuses surrounding the airways are found in all courses from the terminal bronchi to the trachea. Some vessels of the plexus surround the pulmonary arteries and form a periarterial venous plexus, consisting of a sheath of veins encircling a single artery in close apposition (Fig. 13).

\section{DISCUSSION}

The structure of the terminal airways and the bronchovascular relationship in the Baird's whale seen in this study are in accordance with those reported by Henk and Haldiman [9]. The Baird's whale lung has a close association between

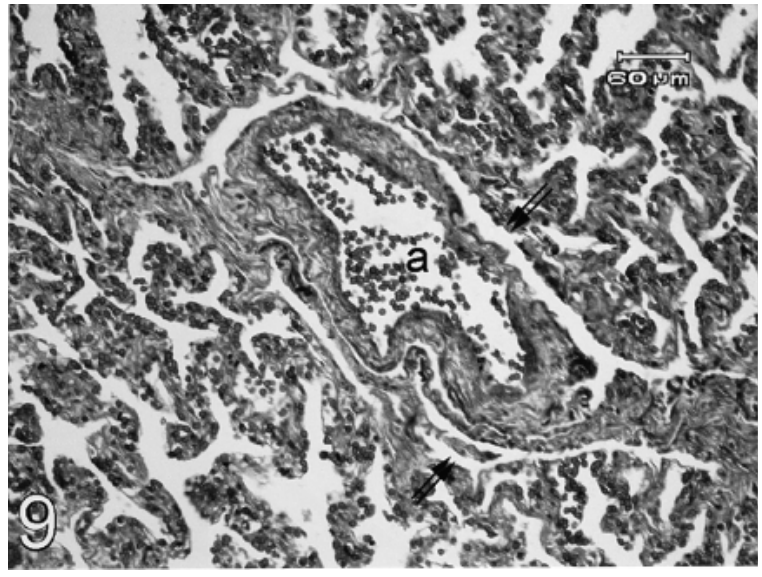

Fig. 9. Cross section of a pulmonary artery (a) surrounded by the vessels of the pulmonary veins (double arrows). Azan Mallory stain. Bar $=60 \mu \mathrm{m}$.

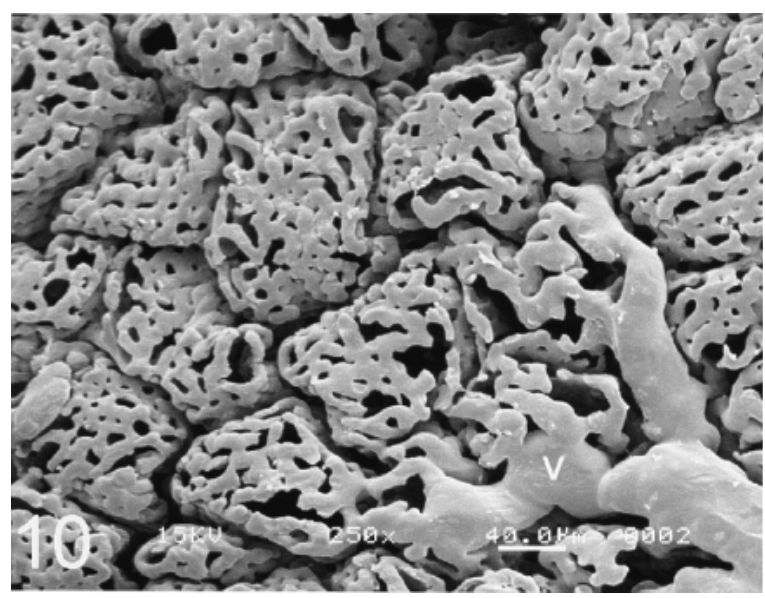

Fig. 10. Corrosion cast of alveolar capillaries abutting against the interlobular connective tissue. Note the capillary layer is single. v: pulmonary venule. $\mathrm{Bar}=40 \mu \mathrm{m}$.

the air passages and the pulmonary circulations, as illustrated by venous plexuses surrounding airways, double capillary beds around alveoli, distinct venous valves and myoelastic sphincters in the terminal or respiratory bronchioles.

An interesting aspect of the microanatomy of the Baird's whale lungs is the consecutive prominent myoelastic sphincters in the terminal bronchioles. These sphincters are characteristic of the terminal airways of other toothed whales like the common porpoise (Delphinus delphis) [4] and the bottlenose dolphin [4]. Similarly, the harbor seal (Phoca vitulina), the elephant seal (Mirounga angustirostris) and the grey seal (Halichoerus grypus) have these myoelastic sphincters [8]. The sphincters are not present in large cetaceans like the bottlenose whale (Hyperoodon ampullatus) [6], the bowhead whales [9] or the Pigmy sperm whale (Kogia brevisceps) (personal observation). According to Goudappel and Slijpper [6], these sphincters do not occur in 


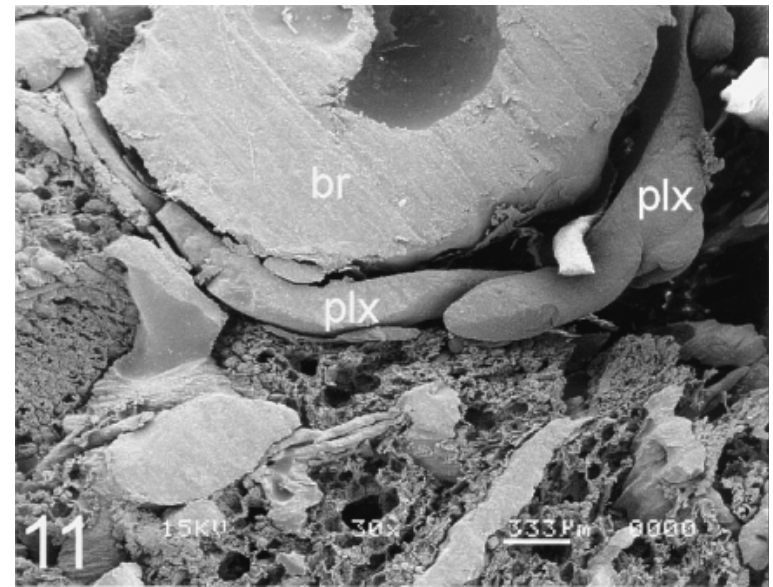

Fig. 11. Cross section of a peripheral portion of a bronchus (br), $2.0 \mathrm{~mm}$ in diameter, surrounded by the plexus (plx) of the pulmonary veins. Note the bronchus and the plexus are in close apposition. $\mathrm{Bar}=333 \mu \mathrm{m}$.

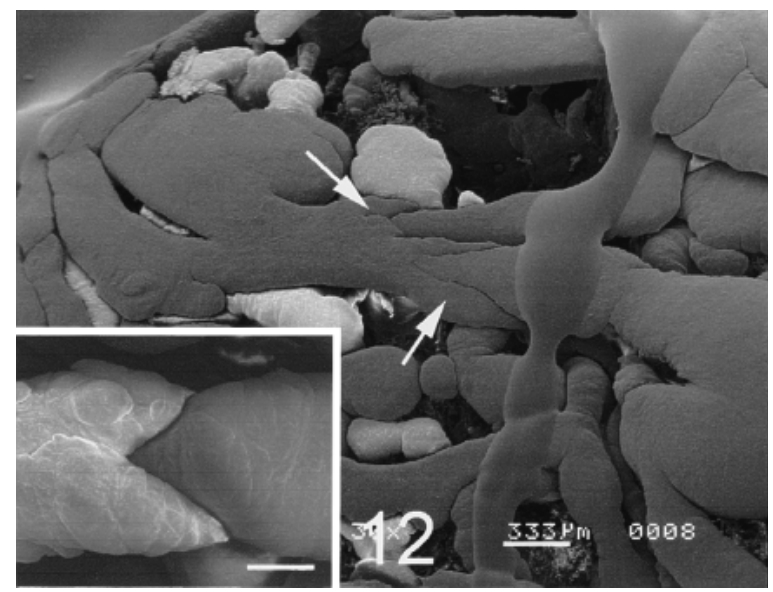

Fig. 12. Corrosion cast of the plexus in the interlobular connective tissue. Note many venous valves (arrows). $B a r=333 \mu \mathrm{m}$. Inset: A paired semilunar venous valve. Bar $=100 \mu \mathrm{m}$.

animals characterized by deep and long intervals between breaths and small lung capacity. They are more distinctive in toothed whales which display a large lung capacity, breathe frequently and dive less deeply. However, the Baird's whale, which is a toothed whale and deep diver with long intervals between breaths, has distinct sphincters. A functional explanation for this discrepancy is not obvious. It could be related to different diving capabilities. Further comparative studies of other whales seem warranted.

The opening of the termination of the bronchus is guarded and closed completely by a sphincter. The sphincters may affect buoyancy during the course of a dive by opening or closing the entrance of the adjacent alveoli to regulate the volume of air in the alveoli. Complete collapse of the alveoli occurs once dolphins have reached pressures equivalent to $65-70 \mathrm{~m}$ in depth [17]. In dolphins, the mag-

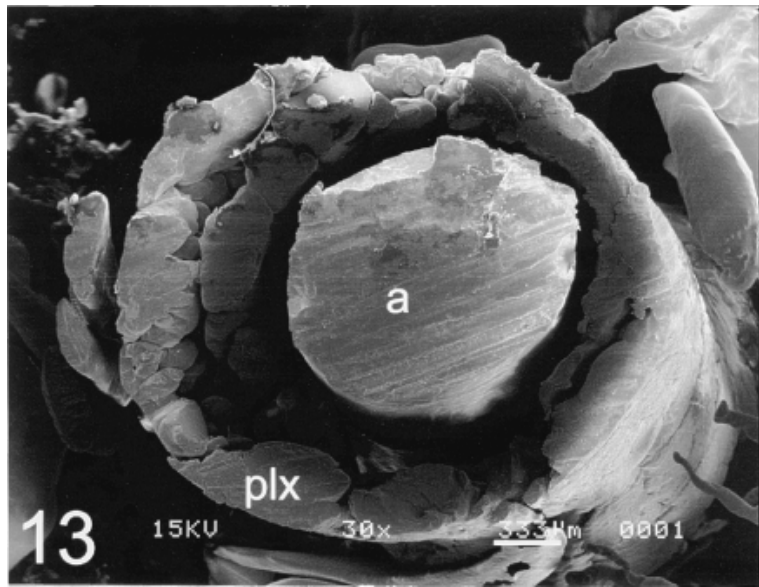

Fig. 13. Cross section of a pulmonary artery (a), $600 \mu \mathrm{m}$ in diameter, surrounded by the venous plexus (plx) of the pulmonary veins. Note these vessels are in close apposition. $\mathrm{Bar}=333 \mu \mathrm{m}$

nitude of the buoyant force changes from positive $(+24.3 \mathrm{~N})$ near the water surface to negative $(-25.7 \mathrm{~N})$ at depths exceeding $67 \mathrm{~m} \mathrm{[17].} \mathrm{The} \mathrm{sphincters} \mathrm{are} \mathrm{responsible} \mathrm{for}$ trapping air in the alveoli and preventing their collapse and a sucking in of alveolar tissue as the dive becomes deeper [4]. Thus, capillary circulation in the alveoli could be secured when the whale initiates a series of cardiovascular changes that include bradycardia and decreased peripheral circulation [19]. As the pressure increases with the depth of the dive, more gas would dissolve in the blood. The entrapment of air in the alveoli during a dive would make more oxygen available for underwater utilization [13]. The presence of 2-3 consecutive sphincters in respiratory bronchioles is indicative of potential for cock activity within these segments. A system of consecutive cocks is used in technical constructions with great differences in pressure on either side of the cock. If the pressure must be regulated by opening the cock now and then, a series of consecutive cocks is preferable to a single one [6]. Furthermore, the sphincter may throttle back on the inflow of air into the alveoli to buffer the mechanical-stress of the alveolar wall on a sudden, maximal flow of tidal air when inspiring.

The most impressive findings in the casts are distinctive plexuses surrounding the pulmonary arteries, in the interlobular connective tissue, and surrounding the airways up to the terminal bronchi. These plexuses are supplied by the pulmonary veins and the blood in the plexus is fully oxygenated. The presence of such plexuses may help in pooling the large volume of blood in the lungs, allowing marine mammals to increase their aerobic dive duration and achieve remarkable depths despite limited oxygen availability when submerged. The existence of the plexus surrounding the pulmonary arteries has not been described in any cetacean. In the plexus of the pulmonary veins surrounding the pulmonary artery, both vessels are in close apposition with a distance of 50-150 $\mu \mathrm{m}$, and venous and arterial bloods mov- 
ing in opposite directions. Typical healthy tissue can be adequately supplied with oxygen by diffusion over distances up to $150 \mu \mathrm{m}$ [5]. This mechanism may enable oxygen diffusion from the pulmonary veins to the pulmonary arteries, supplying oxygen to the pulmonary arterial walls, sphincters and alveolar walls during submergence with alveolar collapse and little pulmonary respiratory exchange.

An abundance of vascular plexuses around the airways has been described in other cetaceans. Goudappel and Slijper [6] suggested that this plexus derived from the pulmonary arteries but the present study of corrosion casts has clearly shown that the plexus consist of anastomosing pulmonary veins. The significance of the plexus beneath the airway epithelium is not apparent. They suggested that this plexus may play a role in heating the air and may act as a shock-absorber [6]. The plexus supplied by the pulmonary veins, (the blood of which contains oxygen), may help sustain respiratory epithelium metabolism and smooth muscle contraction within the lung tissue during prolonged submersion. Lymph vessels are common in the whale lungs [4]. In this study, we also observed distinct lymph-like spaces in the interlobular connective tissue and the septa or alveolar walls. However, whether these spaces are real lymph or a result of the problem associated with tissue sampling is unknown, since the fine structure of the vessels was inconspicuous due to autolysis.

In terrestrial mammals and phocidae, the inhaled air by the mammal is humidified and warmed as it flows past the membranes that line the infolded turbinate membrane of the nasal cavity. Then, when the air reaches the lungs, it is saturated with water vapor and has reached the inner core temperature. The hygroscopic membranes recapture water vapor from the air passing out through its nasal passages, so that the exhaled air can have a relative humidity substantially less than 100 percent, reducing water loss due to evaporation from the respiratory tract. This evaporation will have a cooling effect on the mucosal surface, cooling blood [18]. The whale lacks turbinate bones in the nasal cavity. The humidity and heat exchange between the airflow and the walls of the respiratory passages is far from complete because the total surface area inside the nasal passage is relatively small. The rich vasculature around the respiratory passages from the trachea to the terminal bronchioles and the hygroscopic membranes may replace the function of the nasal cavity.

Another characteristic of Baird' whale lung was the presence of a distinctive venous plexus in the interlobular connective tissue. The significance of this plexus is not known. It may pool the large volume of blood for the whale to draw on an additional store of oxygen such as an isolated pool of oxygenated blood. Interestingly, the vessels of the plexus have many venous valves. These valves may play a role to prevent blood retrograding in elevated venous pressure caused by lung compression at depth. Thoracic collapse begins to occur at $10-50 \mathrm{~m}$ in depth, and alveolar collapse completes at $65-70 \mathrm{~m}$ in depth in the bottlenose dolphin [17]. This may occur in the Baird's whale lung as well. The presence of a large amount of blood in the plexus and lymph in the interlobular connective tissue and the alveolar septa [4] may prevent complete collapse of the lung in deep submergence.

The hyaline cartilage throughout most of the tracheobronchial tree is similar to that of other cetaceans and phocids [4], including the Weddell seal (Leptonychotes weddelli) [1]. Boyd [2] suggested that the presence of cartilaginous support increases the effective dead air space that accommodates most of the air forced from the collapsed alveoli during a dive.

The thick alveolar wall and double capillary bed of the Baird's whale lung is typical of cetaceans, odontocetes and otarids. The significance of the thick alveolar wall is not known. Henk and Haldiman [9] suggest that a thicker alveolar wall may tolerate mechanical stress during the vigorous respiration characteristic in cetaceans. In a previous report, we discussed the double capillary bed in the Baird' whale lung [16].

In summary, the chief contribution of this study would seem to be the establishment of a functional anatomy of terminal air spaces of the Baird's beaked whale lungs. The whale's strategy of oxygen-conservation in the lungs may allow the whale to dive to a depth of 1,000 meters and to remain submerged for as long as $60 \mathrm{~min}$.

ACKNOWLEDGEMENTS. We are gratefully indebted to Mr. Yoshinori Shoji (President of Gaibo Whaling Company) for his gracious permission to sample their whales and Mr. Toshiya Kishiro (National Research Institute of Far Seas Fisheries) and Mr. Sigeo Tabata (Fisheries Agency of Japan) for cooperation in sampling specimens.

\section{REFERENCES}

1. Boshier, D. P. and Hill, P.MCN. 1974. Structural aspects of ventilation and diffusion in the Weddell seal (Leptonychotes weddelli). pp. 197-229. In: Functional Anatomy of Marine Mammals, vol. 2 (Harrison RJ. ed.), Academic Press, New York.

2. Boyd, R. B. 1975. A gross and microscopic study of the respiratory anatomy of the Antarctic Weddell seal, Leptonychotes weddelli. J. Molphol. 147: 309-336.

3. Engel, S. 1966. The respiratory tissue of the Blue whale and the Fin whale. Acta Anat. (Basel). 65: 381-390.

4. Fanning, J. C. and Harrison, R. J. 1974. The structure of the trachea and lungs of the South Australian Bottle-nosed Dolphin. pp. 231-252. In: Functional Anatomy of Marine Mammals. vol. 2 (Harrison, RJ. ed.), Academic Press, New York.

5. Folkman, J. 1976. The vascularization of tumors. Sci. Am. May: $59-72$.

6. Goudappel, J. R. and Slijper, E. J. 1958. Microscopic structure of the lungs of the bottlenose whale. Nature (Lond.) 479: 4633.

7. Haldiman, J. T., Henk, W. G., Henry, R. W., Albert, T. F., Abdelbaki, Y. Z. and Duffield, D. W. 1984. Microanatomy of the major airway mucosa of the bowhead whales, Balaena mysticetus. Anat. Rec. 209: 219-230.

8. Harrison, R. J. and Tomilinson, D. W. 1963. Anatomical and physiological adaptations in diving mammals. pp. 115-162. 
In: Viewpoints in Biology, vol. 2 (Carthy, J. D. and Duddington, C. ZL. eds.), Butterworths, London.

9. Henk, W. G. and Haldiman, J. T. 1990. Microanatomy of the lung of the bowhead whale Balaena mysticetus. Anat. Rec. 226: 187-197.

10. Henry, R. W., Haldiman, J. T., Albert, T. F., Henk, W. G., Abdelbaki, Y. Z. and Duffierld, D. W. 1983. Gross anatomy of the respiratory system of the bowhead whale, Balaena mysticetus. Anat. Rec. 207: 435-449.

11. Ito, T., Kobayashi, K. and Takahashi, Y. 1967. Histological studies on the respiratory tissue in the dolphin lung. Arch. Histol. Jpn. 28: 453-470.

12. Kida, M. Y. 1998. Morphology of the tracheobronchial tree and the route of the pulmonary artery in the fetal minke whale (Balaenoptera acutorostrata). Okajima Folia Anat. Jpn. 75: 251-258.

13. Kooyman, G. L. 1973. Respiratory adaptations in marine mammals. Am. Zool. 13: 457-468.

14. Murata, T. 1951. Histological studies on the respiratory por- tions of the lungs of Cetacea. Sci. Rep. Whales Res. Inst. 6: 3547.

15. Nakakuki, D. 1994. The bronchial tree and lobular division of the lung in the striped dolphin (Stenella coreruleo-albus). J. Vet. Med. Sci. 56: 1209-1211.

16. Ninomiya, H., Inomata, T. and Shirouzu. 2004. Microvasculature in the terminal air spaces of the lungs of the Baird's Beaked Whale (Berardius bairdii). J. Vet. Med. Sci. 66: 14911495.

17. Ridgeway, S. H., Scronce, B. L. and Kanwisher, J. 1969. Respiration and deep diving in the bottlenose porpoise. Science 166: $1651-1654$.

18. Shmidt-Nielsen, K., Crawford, E. C. and Hammel, H. T. 1981. Respiratory water loss in camels. Roc. R. Soc. Lond. B. Biol. Sci. 211: 291-303.

19. Williams, T. M., Davis, R. W., Fuiman, L. A., Francis, J., Le Boeuf, B. J., Horning, M., Calambokidis, J. and Croll, D.A. 2000. Sink or swim: Strategies for cost-efficient diving by marine mammals. Science 288: 133-136. 